\title{
ORGANIZATIONAL SUPPORT AND WORK ENGAGEMENT OF DEAF AND HARD OF HEARING EMPLOYEES: DIVERSITY MANAGEMENT CHALLENGES
}

\author{
Biljana Maleš Mutić, Svetlana Čizmić, Milica Vukelić, \& Ivana B. Petrović \\ Department of Psychology, Faculty of Philosophy, University of Belgrade (Serbia)
}

\begin{abstract}
The management of workforce diversity has been attracting attention among researchers and practitioners in the field of work and organizational psychology over the past ten years. Nevertheless, little is known whether existing concepts, theoretical models and assessment approaches could explain to the utmost work behaviour of minority employees. Work engagement is a positive, affective-motivational state of work-related well-being characterized by vigor, dedication and absorption. As it is deeply embedded in Job Demands-Resources Model (JD-R), it is usually an outcome of job resources such as positive work climate and organizational support. Such supportive climate could be crucial in integrating and supporting diverse workers. It could be particularly challenging to shape the proper form of organizational support for employees that use different channels of communication.

The current study explored the relationship between Work Engagement and Perceived Organizational Support among 101 hard of hearing and deaf persons working at different organizations in Serbia. These concepts were measured with Utrecht Work Engagement Scale (UWES) and Survey of Perceived Organizational Support (SPOS) in paper and pencil form, supported by video translation in Serbian sign language.

Perceived organizational support significantly positively correlated with work engagement in the entire sample of hard of hearing and deaf employees $(r=0.35, p<.001)$. Nevertheless, when subsamples were divided by the degree of hearing impairment $(56-70 \mathrm{~dB} ; 71-90 \mathrm{~dB}$; more than $91 \mathrm{~dB})$, the correlation persisted only among employees with the hearing impairment between $71-90 \mathrm{~dB}(r=0.64, p<.001)$. The correlation was insignificant in groups of employees with the hearing impairment between 56-70dB and with the hearing impairment of more than $91 \mathrm{~dB}$. The significant differences in levels of work engagement were found only between the employees with the hearing impairment between 56-70dB $(M=37.55$, $S D=7.06)$ and employees with the hearing impairment of more than $91 \mathrm{~dB}(M=43.53, S D=6.45)$; $F(2,84)=5.189, p<0.01$.

The results were discussed in the context of complex interplay between level of impairment, work engagement and properly shaped organizational support. The research is solid standpoint for deeper and further research of these concepts within sensitive working populations and provides research input for diversity management.
\end{abstract}

Keywords: Hard of hearing and deaf employees, work engagement, perceived organizational support, diversity management, Serbia.

\section{Introduction}

The management of workforce diversity has been attracting attention among researchers and practitioners in the field of work and organizational psychology over the past ten years (Otaye-Ebede, 2018). In addition to ensuring the presence of minorities in organizations through affirmative actions, it is also of the utmost importance to find means for taking into account their specificities so that their potentials are fully utilized and their well-being supported. There are some studies that show that people with impairment have an equally good or even better performance at work than those without impairment (e.g. Schur, 2002).

Little is known whether existing concepts, theoretical models and assessment approaches could fully explain work behaviour of minority employees. Work engagement is a positive, affective-motivational state of work-related well-being characterized by vigor, dedication and absorption (Bakker, Schaufeli, Leiter \& Taris, 2008). Employees could be engaged when they find their work 
meaningful, when they have feeling that they do a valuable work, and if and when they feel they are able to transform and redirect their work endeavors to effective activities. Engaged employees are, at the same time, cognitively and emotionally connected with their work.

The concept of work engagement is deeply embedded in Job Demands-Resources Model (JD-R) (Bakker \& Demerouti, 2016), and it is usually conceptualized as an outcome of job resources such as positive work climate and organizational support. According to Tims and colleagues (2012), increasing job resources could produce higher levels of work engagement and, thus, equip employees with mechanisms to deal with the negative aspects of job requirements. Social and organizational support is certainly valuable work resource that employees can have in dealing with challenging work demands (Bakker, Demerouti \& Xanthopoulou, 2012). Perceived Organizational Support (POS) has been operationalized as a general belief about the extent to which the organization appreciates contribution of employees and takes care of their well-being (Eisenberger, Huntington, Hutcison, \& Sowa, 1986). Some previous research has shown that there is a positive correlation between perceived organizational support and work engagement and job satisfaction (Caesens \& Stinglhamber, 2014; Rodwell \& Munro, 2013).

Supportive work climate could be crucial in integrating diverse workers. It is particularly challenging to shape a proper form of organizational support for employees that use different communication modalities. A workplace could be seen as a specifically complex environment for employees with sensory (e.g. hearing) impairment, and it is not surprising that many of them have difficulties finding long-term employment. According to some research, employers often emphasize the communication barrier (the important mediator of employers' support), as the most challenging aspect in integration of employees with sensory (e.g. hearing) impairment (Foster, 1992). The quality of the relationship between an employee with sensory impairment and an employer is perceived as a critical factor for maintaining employment, as well as their organizational integration (Allen, Rawlings \& Schildroth, 1989). Employees with sensory impairment have tendency to withdraw from the work environment that is highly challenging for them (Scherich, 1996), e.g. a team work that implies simultaneous communication. Thus, the aim of the current study was to explore the relationship between perceived organizational support and work engagement among hard of hearing and deaf persons working at different organizations in Serbia.

\section{Method}

\subsection{Procedure and sample}

The sample comprised of 101 hard of hearing and deaf employees (49.5\% were women, $91 \%$ with secondary education) from various publicly and privately owned organizations, from Serbia. Participation in this research was anonymous, voluntary and not compensated. There were $8.9 \%$ of employees with hearing impairment between 20 and $40 \mathrm{~dB} ; 5 \%$ with hearing impairment between 41 and $55 \mathrm{~dB} ; 19.8 \%$ with hearing impairment between $56-70 \mathrm{~dB} ; 32.7 \%$ employees with hearing impairment between $71-90 \mathrm{~dB}$, and $33.7 \%$ with hearing impairment of more than $91 \mathrm{~dB}$.

\subsection{Instruments}

Work Engagement was measured by the Serbian short version of the Utrecht Work Engagement Scale, UWES-S (Petrović, Vukelić \& Čizmić, 2017) that consists of nine items followed by a seven-point scale (from $0=$ Never, to 6 = Always), Cronbach's alpha coefficient was 0.90 . The perceived organizational support was measured using the Serbian version of the 8-item form of the Survey of Perceived Organizational Support, SPOS (Eisenberger et al., 1986), previously used in research on a large sample of employees from Serbia (Vukelić, Čizmić, Petrović, Tenjović \& Giorgi, 2015). Each SPOS item was followed by a 7-point Likert scale, Cronbach's alpha coefficient was 0.87 . Both scales were translated into Serbian sign language and presented in form of a video. After seeing each video-statement (fully translated with Likert scale anchors), employees were entering their responses in the printed paper form of the questionnaire. Questionnaire was followed by sociodemographic inventory. Cronbach's alpha coefficient of the Serbian sign language version of UWES-9 was 0.81, while Cronbach's alpha for the Serbian sign language version of SPOS-8 was 0.83 . 


\section{Results}

The results have shown that perceived organizational support significantly positively correlated with work engagement in the entire sample of hard of hearing and deaf working persons $(\mathrm{r}=0.35, \mathrm{p}<.001)$. Nevertheless, when subsamples were divided by the degree of hearing impairment (56-70 dB; 71-90 dB; more than $91 \mathrm{~dB}$ ), the correlation persisted only among employees with the hearing impairment between 71-90 dB $(r=0.64, \mathrm{p}<.001)$. The most affirmatively evaluated statements of SPOS within this group were: the organization takes pride in my accomplishments at work (with $64 \%$ answers moderately to strongly agree) and the organization would take into the account and respect my complaints (also 64\% answers moderately to strongly agree). The correlation was insignificant in the group of employees with the hearing impairment between 56-70 dB and with the hearing impairment of more than $91 \mathrm{~dB}$. The significant differences in the level of work engagement were found only between the employees with the hearing impairment between 56-70 dB and employees with the hearing impairment of more than $91 \mathrm{~dB}$ (Table 1); F(2,84) = 5.189, $\mathrm{p}<.01, \eta 2=0.11$.

Table 1. Means and standard deviations of work engagement for groups of employees with different levels of hearing impairment.

\begin{tabular}{ccc}
\hline Level of hearing impairment $(\mathrm{dB})$ & $M$ & $S D$ \\
\hline $56-70$ & 4.17 & .78 \\
$71-90$ & 4.42 & .82 \\
91 and more & 4.84 & .72 \\
\hline
\end{tabular}

\section{Conclusion}

Presented research has raised several important questions. The first one is the nature and intensity of relations between organizational support and work engagement within different segments of employees with hearing impairment. It is also necessary to understand all social, work and emotional aspects that could affect work engagement and productivity of employees with hearing impairment. Future research would benefit from mixed-method approach as qualitative exploration could give deeper insight into diverse workforce perception of organizational social circumstances. The results can be fully understood only with taking into the account complex interplay between level of impairment, work engagement and organizational support. The second one is the necessity of translating and/or adjusting the assessment approach for employees with sensory impairment both carefully considering both the questions/statements and the answers/rating scales. In order to be able to shape interventions that would cover diverse workforce, it is necessary for employers to establish well-designed and meaningful assessments (Otaye-Ebede, 2018). The research is solid standpoint for deeper and further research of these concepts within sensitive working populations and provides research input for diversity management. The most important practical implication of the presented research is the cautionary advice for organizational consultants to carefully check assessment instruments aimed for exploring and developing organizational interventions that should cover diverse workforce.

\section{References}

Allen, T. E., Rawlings, B. W. \& Schildroth, A.N. (1989). Deaf students and the school-to-work transition. Baltimore, USA: Paul H. Brooks Publishing.

Bakker, A. B., \& Demerouti, E. (2016). Job demands-resources theory: taking stock and looking forward. Journal of Occupational Health Psychology, 22(3), 273-285. doi: 10.1037/ocp0000056

Bakker, A. B., Demerouti, E., \& Xanthopoulou, D. (2012). How do engaged employees stay engaged. Ciencia \& Trabajo, 14(1), 15-21.

Bakker, A. B., Schaufeli, W. B., Leiter, M. P., \& Taris, T. W. (2008). Work engagement: An emerging concept in occupational health psychology. Work \& stress, 22(3), 187-200. doi: 10.1080/02678370802393649

Caesens, G., \& Stinglhamber, F. (2014). The relationship between perceived organizational support and work engagement: The role of self-efficacy and its outcomes. Revue Européenne de Psychologie Appliquée/European Review of Applied Psychology, 64(5), 259-267. doi: 10.1016/j.erap.2014.08.002 
Eisenberger, R., Huntington, R., Hutchison, S., \& Sowa, D. (1986). Perceived organizational support. Journal of Applied Psychology, 71(3), 500-507. doi: 0021-9010/86

Foster, S. B. (1987). Employment experiences of deaf college graduates: An interview study. Journal of Rehabilitation of the Deaf, 21(1), 1-15.

Otaye-Ebede, L. (2018). Employees' perception of diversity management practices: scale development and validation. European Journal of Work and Organizational Psychology, 27(4), 462-476. doi: 10.1080/1359432X.2018.1477130

Petrović, I. B., Vukelić, M., \& Čizmić, S. (2017). Work engagement in Serbia: Psychometric properties of the Serbian version of the Utrecht Work Engagement Scale (UWES). Frontiers in Psychology, 8, 1799. doi: 10.3389/fpsyg.2017.01799

Rodwell, J., \& Munro, L. (2013). Well-being, satisfaction and commitment: the substitutable nature of resources for maternity hospital nurses. Journal of advanced nursing, 69(10), 2218-2228. doi: 10.1111/jan.12096

Scherich, D. L. (1996). Job accommodations of persons who are deaf or hard of hearing: Current practices and recommendations. Journal of Rehabilitation, 62(2), 27-35.

Schur, L. (2002). The Difference a Job Makes: The Effects of Employment Among People with Disabilities. Journal of Economic, 36(2), 339-347. doi: 10.1080/00213624.2002.11506476

Tims, M., Bakker, A. B. \& Derks, D. (2012). The development and validation of the Job Crafting Scale. Journal of Vocational Behavior, 80(1), 173-186. doi: 10.1016/j.jvb.2011.05.009

Vukelić, M., Čizmić, S., Petrović, I. B., Tenjović, L., \& Giorgi, G. (2015). Psychometric properties of the Serbian version of the negative acts questionnaire: Revised. Psihologija, 48(1), 19-33. doi: 10.2298/PSI1501019V 